the least important contributors to the country's wealth and may well become a dominant factor. Increased burdens will be placed on the nation's chemists and chemical engineers, and their training must be such that they can achieve the tasks that lie ahead. Care must be taken that the new Department is continually nourished by its roots-the subjects of chemistry, physics, mathematics and engineering; and those who pass through it should then build on sure foundations.

\section{U.S. Research Board for National Security}

EstaBLISHMENT of the Research Board for National Security by the U.S. National Academy of Sciences was announced on February 11 by Mr. Henry L. Stimson, U.S. Secretary of War, Mr. James Forrestal, U.S. Secretary of the Navy, and Dr. Frank B. Jewett, president of the National Academy of Sciences. The Executive Committee of the new Board will be headed by Dr. Karl T. Compton, president of the Massachusetts Institute of Technology, and the Board will consist of seventeen civilian men of science and nine representatives each from the army and navy, including Major-General Norman T. Kirk, Army Surgeon-General, and Vice-Admiral Ross T. McIntire, chief of the U.S. Navy Bureau of Medicine and Surgery. Civilian members include Mr. Herbert S. Gasser, director of the Rockefeller Institute for Medical Research, Prof. E. O. Lawrence, professor of physics at the University of California in Berkeley, and Prof. Isador I. Rabi, professor of physics at Columbia University. The Secretaries of War and Navy requested the president of the National Academy of Sciences under its congressional charter to (stablish the Board "to assist in providing for continued eivilian participation in the longer-term scientific problems of national security when the Office of Scientific Research and Development proceeds to liquidate its activities as a temporary wartime agency. . . The objective of the Board will be to continue, pending final consideration by Congress on creation of an independent agency, the close co-operation between civilian scientists and the armed services which has proven to be such a vital element in the prosecution of the war. Composed of highranking officers responsible for the needs and plans of the Army and Navy with an equal number of distinguished representatives of science, engineering, medicine and industry, this Board includes many of the features of the Office of Scientific Research and Development which has proven so successful as a war-time agency in mobilising civilian scientists and coordinating their work with the requirements and operations of the armed services. . . ." The announcement pointed out that "science is here broadly interpreted to include the employment of scientific method of analysis, experiments and tests in any branch of science or technology including engineering, medicine, psychology and biology."

\section{Science and Planning}

In a memorandum "Science and the Real Freedoms" issued by the Association of Scientific Workers (price 3d.), Sir Robert Watson-Watt gives a very fair appraisal, under the title "Freedoms of Science", of the issue between planning and freedom, successfully avoiding the political prejudices with which the discussion is apt to become entangled. Sir Robert's article is based on a speech delivered in Manchester last October. He insists first on the necessity for clearly defining our terms. Science he regards as organized knowledge; but he considers that those constructive pursuits requiring for their prosecution, expansion and usefulness the application of a like process of thought are also properly covered by the term 'scientific'. The pure and applied sciences are in fact planned sciences. There is no human activity which is not a planned activity, and Sir Robert urged that we should consider whether organization in hope is not a nobler and more fruitful aspect of human endeavour than the organization of and through fear which has inspired our planning for war and even extended to the medical sciences. Asserting that the freodom to learn, to choose, to think, to work and to speak are the fundamental freedoms of the individual and the pillars of any tolerable society, Sir Robert urged that the real question is whether planning - which is inevitable-is to be open and public, or sectional, secret or selfish. He visualizes a structure in which the user who wants a definite result asks the research worker, the developer and the producer how best, by what particular kind of planning, he can attain his result; the research worker, the developer and the producer co-operate with the user, indicating to him the full possibilities. The greatest danger is over-simplification; but the planning of science in the application to national life is possible with no substantial risk to the freedom of fundamental science.

\section{Education and Training for Engineers}

IN a second report now issued by the Institution of Electrical Engineers, it is suggested that provision should be made for the education of craftsmen, technicians and professional engineers. There should be a three-year course for a craftsman certificate, followed by a more general course, lasting two years, in worleshop administration. For the technicians group, the existing course for the ordinary national certificate in electrical and mechanical engineering should be co-ordinated as a basic course, and this should be followed, where necessary, by a course in advanced technology. Students who do well in the first two years of the ordinary certificate course should be combined with those who have reached the standard of a good school certificate in mathematics and physics, and these students should enter a two-year course leading to an intermediate national certificate designed to meet the requirements of the Section A examinations of the Institutions of Civil, Mechanical and Electrical Engineers. These courses would lead to the higher national certificates in electrical engineering and kindred subjects. Another section of the report contains proposals for the further education and training of electrical engineers returning from the Services.

\section{University of Birmingham}

THE Court of Governors of the University of Birmingham has nominated Mr. Anthony Eden for appointment as Chancellor of the University in succession to Lord Robert Cecil. The Pro-Chancellor (Mr. E. P. Beale) has announced that a public appeal for $£ 1,000,000$ will shortly be made to enable the University to proceed with urgently needed developments, especially the bringing together on one site of all the departments (some of which still remain in the centre of the city) and the building of additional halls of residence. Many of the donors to the appeal for $£ 250,000$ for rebuilding and re-equipping the Departments of Mechanical and Electrical Engineering have expressed the opinion that a great need of 
the provincial universities is a fuller communal life for the students, such as can be secured by halls of residence.

\section{Electric Discharge Lamps for Photography}

Mr. H. K. BouRne presented a paper on this subject, illustrated by a comprehensive display of typical lamps, at a meeting of the Association for Scientific Photography on January 27. Photographically, electric discharge lamps have high actinic efficiency combined with low heating power; and they have a long life. Since the early days of the Cooper-Hewitt lamp, a glass tube several feet in length with a mercury pool at the end, development has proceeded along two divergent lines, low pressure and high pressure. In the modern low-pressure lamp, the pressure of mercury vapour is only a fraction of a millimetre; it emits considerable long- and shortwave ultra-violet radiation, which by means of fluorescent powders on the inside of the tube is converted to visible light of longer wave-lengths. It provides a well-diffused light-source closely resembling daylight and capable of giving accurate colour rendering. The high-pressure mercury vapour lamp consists of an inner glass tube containing the arc, sealed into an outer glass jacket. The arc tube pressure is about 1 atmosphere, and the arc is constricted into a narrow cord along the axis of the tube. The outer envelope is filled with an inert atmosphere. There is a wide range of types, the most powerful being in powers of the order of $10 \mathrm{~kW}$. or higher, with a brightness ranging up to 100,000 candles per sq. $\mathrm{cm}$. The spectrum is linear in character, and fluorescent powders cannot be used with the high brightness lamps; but with increasing pressure there is an improvement in the colour, the main lines broadening while the amount of continuous background increases. An amalgam of cadmium is sometimes used to improve colour. Brightness increases with increases of loading per unit length in the are column, which has been made possible, first by the use of quartz tubes with molybdenum foil vacuum-tight seals, and later by the introduction of water-cooling, which dissipates approximately 70 per cent of the radiated heat. The author described a number of lamps including a compact source lamp with a maximum brightness of 18,000 c./sq. cm., a self-contained metal box-lamp which can be used without a lamphouse for the illumination of laboratory instruments, a 100-hourlife water-cooled high-pressure lamp with a luminous efficiency of 65 lumens per watt, a peak brightness of $30,000 \mathrm{c} / \mathrm{sq} . \mathrm{cm}$. and an internal pressure of about 75 atmospheres, and the B.T.H. syroposcopic tube which can give recurring flashes at a predetermined frequency or be employed as a synchronized flashlamp for ordinary photography.

\section{Resources of Ireland}

IN celebration of the centenary of the publication of Sir Robert Kane's "Industrial Resources of Ireland", the Royal Dublin Society has published (price $2 s$. 6d.) a number of lectures delivered before the Society last August, under the general title of "The Natural Resources of Ireland". Prof. M. A. Hogan, in reviewing the fuel resources of the country, does not see much hope of increased coal production, but believes that resources of the limited coalfields are sufficient to last at least 250 years. He foresees, on the other hand, a great increase in the use of turf, provided that mechanized means of cutting it can be:devised. This would entail the preliminary easy drainage of large areas of bog, in order to bear the weight of heavy cutting machines. Mr. J. A. O'Riordan discusses the possibilities of water power. The Shannon and Liffey schemes have made a notable beginning, and their theoretical capacity is estimated at 84,000 horse-power. Gauging stations on other rivers and possibilities, still unmeasured, of smaller streams, promise great accretion to these resources. Mr. O'Riordan thinks that the potential production of hydro-electric power could eventually be doubled. It is to her water-power resources that Ireland must clearly look for energy in the future. A review of the mineral resources other than fuel, by Mr. D. W. Bishop, shows little of importance except phosphates. The metallic mineral resources are very small. Some ores, in small supply, seem to have been exhausted.

\section{Studies on Pollen Analysis}

THE study of pollen has come much to the fore during recent years. The pollen analysis of peat has become one of the most important techniques used in the study of post-glacial vegetation. Partly in view of the necessity of studying such geological data in terms of processes now in operation and partly in order to obtain information relating to plant allergens, research is now being directed toward fundamental problems relating to the liberation, dispersal and deposition of air-borne pollen. The results will have obvious implications in the field of floral biology and should also be of value to the meteorologist. The pollen of insect flowers is receiving attention as a means of determining the source of samples of honey. All the above studies have, up to the present, been referred to under the general heading of pollen analysis. The need for a better name has been expressed in Pollen Analysis Circular, a' cyclostyled research bulletin edited by Prof. Paul B. Sears, of Oberlin College, Ohio. Messrs. H. A. Hyde and D. A. Williams, of the National Museum of Wales and Llandough Hospital, Cardiff, respectively, in the October issue of that Circular suggest the term palynology (Gk. $\pi \alpha \lambda u v \omega$ (paluno), to strew or sprinkle; cf. $\pi \alpha^{\prime} \lambda \eta$ (palē), fine meal; cognate with Latin pollen, flour, dust) for the study of pollen and other spores and their dispersal, and applications thereof. It is hoped that the sequence of consonants p-l-n (suggesting pollen, but with a difference) and the general euphony of the new word will commend it.

\section{Motor Control-Gear}

A PAPER read recently in London by D. Rudd before the Institution of Electrical Engineers reviews, in general terms, present-day practice in the design of industrial motor control-gear. The scope of the paper is limited to standard industrial equipment and the subject is approached from the user point of view. The first part reviews the principles on which modern design has been established, and the later sections discuss some of the factors that are likely to affect future development. The author states the case for the utmost simplicity in design and for greater latitude in the value of allowable starting-current peaks. Possible development in contact materials is discussed, and reference is made to the possibility of achieving some measure of standardization.

\section{Veterinary Medical Institute}

According to the December issue of the AngloSwedish Review a new veterinary-medical institute has recently been inaugurated in the northern out- 